\title{
Trained Nurse-led education and counseling of heart failure self- care model "PrOMiSe" decrease clinical outcome on re-admission and/ or mortality in heart failure patients in hospital, Indonesia
}

\author{
Rita Sekarsari ${ }^{1}$, EllyNuracmah ${ }^{2}$, RatnaSitorus ${ }^{3}$ andAnwar Santoso ${ }^{4}$ \\ ${ }^{I}$ Doctorate student in Faculty of Nursing, University of Indonesia \\ ${ }^{2}$ Faculty of Nursing, University of Indonesia \\ ${ }^{3}$ Faculty of Nursing, University of Indonesia \\ ${ }^{4}$ Cardiac Centre HospitalHarapan Kita, Jakarta
}

\begin{abstract}
: the objective of this study is to determine the effect of nurse-led education and counseling of heart failure self-care model "PrOMiSe"todecreasere-admission and/or mortality inheart failure patients. We used a three-model integrated approach, the Transtheoretical, Orem and Motivational interviewing model, or simply termed "PrOmiSe".Quasi-experimental with control group design was used in this study. One hundredparticipants with heart failure were enrolled during their hospitalization. The intervention group received 5 education sessions during hospitalization, 3 education and counseling sessions during outpatient clinic visits and 2 telephone calls over a three month period from a trained nurse. Meanwhile, the control group received usual care. Statistical analysis was performed using independentt-test, ChiSquare,Mann-Whitney test,KaplanMeierandCoxregression test. Results: Nurse-ledmodel "PrOmiSe"revealed that there aresignificantdifferences in the reduction of the re-admission and/or mortality rates after 6 months of the patients were given intervention. Conclusion: The education and counseling of heart failure self-care model "PrOmiSe" is effective in reducing the rates of re-admission and/or mortality in heart failure patients. This method is applicable to be used as one of the education and counseling models for heart failure self-care in other hospitals.
\end{abstract}

Keywords: heart failure patient, nurse, PrOMiSe model, re-admission and/ ormortality, self-care

\section{Introduction}

Cardiovascular diseases remain as the leading cause of mortality both worldwide and in the United States, accounting for 41 percent of all mortalitys. ${ }^{1}$ Theyresult in high rate of hospital re-admission and mortality. Heart failure is the end stage of cardiac disease after the myocardium has used all its reserve and compensatory mechanisms. Once the overt signs appear, half of the patients would die within 5 years despite medical management. ${ }^{2}$ The risk of heart failure isincreased two to six-fold with coronary heart disease. ${ }^{1}$ According to the American Heart Association, nearly 5 million Americans are living with heart failure and 550,000 new cases are diagnosed each year, with mortality rates as high as $50 \%$ within 5 years since diagnosis. ${ }^{3,4}$ Unfortunately, there has not been any national mortality and morbidity data for cardiovascular diseases in Indonesia, particularly for the incidence of heart failure. As an illustration, the "Harapan Kita" National Cardiac Center Hospital Jakarta, the largest cardiovascular services provider in Indonesia, reported that congestive heart failureaccount for up to $18 \%$ of the patients, which is the second most commonly reported heart disease after atherosclerosis $23 \%$. Heart failure accounts for nearly $26 \%$ of all mortality causes and approximately $14 \%$ of patients were reported to have two to seven re-admissions in one year. ${ }^{5}$

The data above shows that despite being supported by science and technological advancement in the treatment of heart failure in developed and developing countries, the incidence of heart failure is still high. The condition creates a burden for both patients and family and increase heath care cost, especially for patients with frequent re-hospitalizations. ${ }^{6}$ Therefore, ongoing care for the management of heart failure should not only be focused in state-of-the-art medical treatment, but also targeted for behavioral changes.

Based on several studies, there was a significant correlation between of rate heart failure-related hospital re-admission and the advance practice of nurse-led telephone intervention, education and counseling compared to usual care; the intervention group which received advance practice nurse intervention reported fewer hospital re-admission, improved survival and self-care behavior for a person with heart failure, and lower mortality rate and days of hospitalization. ${ }^{7,8,9,10,11,12,13,4}$ Thus, it is clear that education and counseling led by nurse is an effective and critical component to improve the clinical outcome of heart failure patients.

One of the intervention models developed to improve clinical outcome is theintegrated education and counseling of heart failure self-care model, which is integrated in the ProchaskaTranstheoretical, Orem SelfCare, Miller Motivational Interviewing and researcher Sekarsari model. It is also termed as the integrated 
education and counseling of heart failure self-care or "PrOMiSe" model. The intervention of "ProMiSe" model is aimed to assess and address the patient's readiness to behavioral change utilized the concepts of transtheoretical model, which include pre-contemplation, contemplation, preparation, action, maintenance, and termination. The stages of change of heart failure patients are used as the basis to provide supportive education (Orem model) while simultaneously providing counseling about self-care in heart failure using motivational interviewing approach. Using the "ProMiSe" model, heart failure patients are expected to be active and participative, more open, competent and capable of making their own decision regarding the choice of behavior to maintain their physiologic stability (maintenance) and to response to any symptoms if they occur (management). As a result, the model could increase patient's survival as well as decrease the rates of readmission and/ or mortality of heart failure patients.

To date, there has not been any integrated education and counseling for heart failure self-care model in Indonesia. Therefore, patients usually lack information about heart failure, healthcare providers have inadequate skills to manage heart failure, and rates of re-admission and mortality are still high. Based on these conditions, we are interested to develop an integrated education and counseling for heart failure self-care model "ProMiSe" in our hospital.

\subsection{Research Question}

In order to achieve the objectives, the researchquestions are:

1.1.1 What are the demographic characteristics of the patients with heart failure in this hospital setting?

1.1.2 Does nurse-led integrated education and counseling of heart failure self-care"PrOMiSe" model effective to prolog the survival of heart failure patients ?.

1.1.3 Isnurse-led integrated education and counseling of heart failure self-care "PrOMiSe"modeleffective to reduce re-admission and/or mortality rates of heart failure patients?

\subsection{Research Hypothesis}

1.2.1 The survival of heart failure patient in the group who received the intervention of integrated education and counseling of heart failure self-care "PrOMiSe" model is longer compared to control groupafter 6 months of theinterventionmodel.

1.2.2 The re-admission and/or mortality rates of heart failure patients in the group who received intervention of integrated education and counseling of heart failure self-care "PrOMiSe" model are lower compared to control group after 6 months of theinterventionmodel.

\section{a. Design}

\section{Methods}

Quasi-experimental with control group design was used in this study. One-hundredparticipants with Class II-III NYHA classificationof heart failure were enrolled during their hospitalization in Cardiac Centre Hospital Harapan Kita, Jakarta, Indonesia. The intervention group received five education sessions and counseling during hospitalization, three education and counseling sessions in outpatient clinic and two telephone calls over a three-month period. In addition, the intervention group was provided withfive different booklets (written material about heart failure and self-care management) and two monitoring books about monitoring drugs therapy, and weight and fluids monitoring. Each education and counseling intervention was a one-on-one session with the duration of 45-60 minute. Meanwhile, each telephone call for education and counseling intervention was performed with the duration of 5-10 minutes. The control group received one education session asper usual standard management without written material. The intervention of integrated education and counseling of heart failure self-care "PrOMiSe" model was provided by a team of trained cardiovascular nurses. The clinical experience of the team members of trained cardiovascular nurses was 10 years of working in the cardiovascular care unit. The team members received a training, which includes 6 hour-session regarding the instruction for the integrated education and counseling of heart failure self-care "ProMise" model by the main researchers; a 6-hour session regarding the management of heart failure by a cardiologist; and a 12-hour session regarding the concept, theory and strategy of education and counseling by a psychologist and a nurse consultant. Statistical analysis was performed using independentt-test, ChiSquare, Mann-WhitneyTest, KaplanMeierandCoxregression.Evaluation was carried out after 6 months of the interventionof integrated education and counseling of heart failure self-care "PrOMiSe"model.

\subsection{Population and Sample}

The population of this study are patients who had a confirmed diagnosis of heart failure who met the inclusion criteria, which include: 1) adults with NYHA functional class II-III heart failure with the etiology of hypertension or coronary artery disease, 2) capable of speaking and reading Bahasa Indonesia, 3) have cognitive physical and cognitive ability to participate, 4) do not have a history of cardiac surgery, 5) residence of Jakarta, 
Bogor Depok, Tangerang, and Bekasi (Jabodetabek) area, 6) consented to participate in the study, 7) have access to telephone calls. Participants with chronic diseases with symptoms relevant with heart failure were excluded from the study. The sample consisted of 100 consecutive participants with NYHA functional class IIIII heart failure; 50 samples were allocated into the intervention and control group, respectively. One participant in intervention group and one in control group dropped out of the study. There were 2 and 9 deaths reported on the intervention group and control group, respectively.

\section{b. Measurement tools}

Demographic characteristics of the participants collected by questionnaire include: age, gender, marital status, level of education, job, functional class on heart failure (NYHA), ejection fraction, systolic blood pressure, diastolic blood pressure, and comorbidities. These questionnaires were also used for the follow up of re-admission and mortality rates; the first admission was considered for those admitted from problems directly related to heart failure and mortality. Heart failure-related hospital re-admissions were reported by the participants as requested and from the medical records of the hospital. Meanwhile, events of mortality were assessed through telephone calls to the family

\section{c. Data analysis}

Bivariate analysis was performed to determine equity on two groups (intervention and control) for all research variables. Statistical tests for this study include independent t-test (numeric data which normal distributed), Mann Whitney (numeric data which abnormal distributed)and chi-square test (categoricaldata). Moreover, Kaplan Meier was used to analyze survival time and cox regression was used to determine relative risk for clinical outcome of re-admission or mortality of heart failure patients.

\section{Results}

The results of this study describe demographic and clinical characteristics of the subjects, length of survival for heart failure patients, clinical outcome of re-admission and/or mortality of heart failure participant after 6 months of theintegrated education and counseling of heart failure self-care"PrOMiSe"model had been performed.

\subsection{Subjects characteristics}

One-hundredparticipants with NYHA class II-III heart failure who were hospitalized in the Cardiac Centre Hospital Harapan Kita, Jakarta, Indonesia were enrolled in this study. We performed consecutive sampling and allocated the subjects into either the control group $(n=50)$ and to the intervention group $(n=50)$. Demographic and clinical characteristic of the participants are shown in Table 1 below.

Table 1 Demographic and Clinical Characteristics of the Sample (N=100)

\begin{tabular}{|c|c|c|c|c|}
\hline Characteristics & & Intervension $(\mathrm{n}=50)$ & $\begin{array}{l}\text { Control } \\
(\mathrm{n}=50)\end{array}$ & p-value \\
\hline \multirow[t]{3}{*}{ Age } & & & & 0,062 \\
\hline & Median & 55 & 58,5 & \\
\hline & Mean \pm SD & $54,90 \pm 9,62$ & $58,74 \pm 10,65$ & \\
\hline \multirow[t]{3}{*}{ Gender } & & & & 0,133 \\
\hline & Male & $30(60,0 \%)$ & $38(76,0 \%)$ & \\
\hline & Female & $20(40,0 \%)$ & $12(24,0 \%)$ & \\
\hline \multirow[t]{3}{*}{ Marital Status } & & & & 1,000 \\
\hline & Married & $48(96,0 \%)$ & $49(98,0 \%)$ & \\
\hline & Single & $2(4,0 \%)$ & $1(2,0 \%)$ & \\
\hline \multirow[t]{4}{*}{ Education } & & & & 0,906 \\
\hline & Junior school & $15(30,0 \%)$ & $11(22,0 \%)$ & \\
\hline & High School & $25(50,0 \%)$ & $26(52,0 \%)$ & \\
\hline & Graduate school & $10(20,0 \%)$ & $13(26,0 \%)$ & \\
\hline \multirow[t]{3}{*}{ Job } & & & & 0,541 \\
\hline & Employ & $22(44,0 \%)$ & $18(36,0 \%)$ & \\
\hline & Unemployed & $28(56,0 \%)$ & $32(64,0 \%)$ & \\
\hline \multirow[t]{2}{*}{ Ejection Fraction } & & & & 0,085 \\
\hline & Median & 27 & 24,5 & \\
\hline \multirow[t]{2}{*}{ Systolic Blood Pressure } & & & & 0,233 \\
\hline & Median & 115,00 & 120,00 & \\
\hline \multirow[t]{3}{*}{ Diastolic Blood Pressure } & & & & 0,794 \\
\hline & Median & 77,00 & 76,00 & \\
\hline & Mean \pm SD & $77,65 \pm 14,57$ & $76,90 \pm 14,02$ & \\
\hline \multirow[t]{4}{*}{ NYHA functional class } & & & & 0,679 \\
\hline & Class II & $20(40,0 \%)$ & $17(34,0 \%)$ & \\
\hline & Class III & $30(60,0 \%)$ & $33(66,0 \%)$ & \\
\hline & & & & 0,815 \\
\hline
\end{tabular}


Comorbidity

\begin{tabular}{|c|c|c|c|c|}
\hline \multirow{5}{*}{ Etiology } & Without comorbidity & $13(26 \%)$ & $11(22 \%)$ & \multirow{5}{*}{0,368} \\
\hline & With comorbidity & $37(74 \%)$ & $39(78 \%)$ & \\
\hline & & & & \\
\hline & HHD & $34(68 \%)$ & $39(78 \%)$ & \\
\hline & CAD & $16(32 \%)$ & $11(22 \%)$ & \\
\hline
\end{tabular}

The most common clinical feature on both group was hypertension (68\% vs $78 \%, \mathrm{p}>0.05)$. Furthermore, means of participants' age on intervention group and control group were 54.90 years $( \pm 9.62)$ and 58.74 years $( \pm 10.65)$, respectively. The majority of patients were men, married, had finished senior high school as the last level of education, and unemployed. The proportion of unemployed subjects in control group was higher than intervention group (64.0\% vs $56.0 \%$, respectively).

Independent t-test shows no differences of age and diastolic blood pressure between intervention and control group $(\mathrm{p}>0.05)$. Chi-square test showed no differences of participant's characteristics on gender, marital status, education, job, NYHA functional class and comorbidity between intervention and controlgroup ( $p$ $>0.05$ ). Moreover, Mann-Withney test reveals no differences of ejection fraction and systolic blood pressure between intervention and control group $(\mathrm{p}>0.05)$. Therefore, characteristics participant on both groups are homogeny.

\subsection{Time of survival and clinical outcome of readmission and or death}

Table 2. Log Rank test of clinical outcome of time of survival, re-admissionand/ ormortality in intervention group and control group after 6 months ofintervention of education and counseling of heart failure self-care "PrOMiSe" model.

\begin{tabular}{llllll}
\hline \multirow{2}{*}{ Group } & \multicolumn{2}{c}{ Readmission and or death } & Censored & Survival time & p-value \\
\cline { 2 - 6 } & $\mathrm{n}(\%)$ & $\mathrm{n}(\%)$ & Mean & SE & .037 \\
\hline Intervention & $22(40 \%)$ & $28(56 \%)$ & 125.420 & 9.656 & \\
Control & $33(60 \%)$ & $17(34 \%)$ & 107.408 & 9.510 & \\
& & & & & \\
Total & $55(55 \%)$ & $45(45 \%)$ & 116.868 & 6.800 & \\
\hline
\end{tabular}

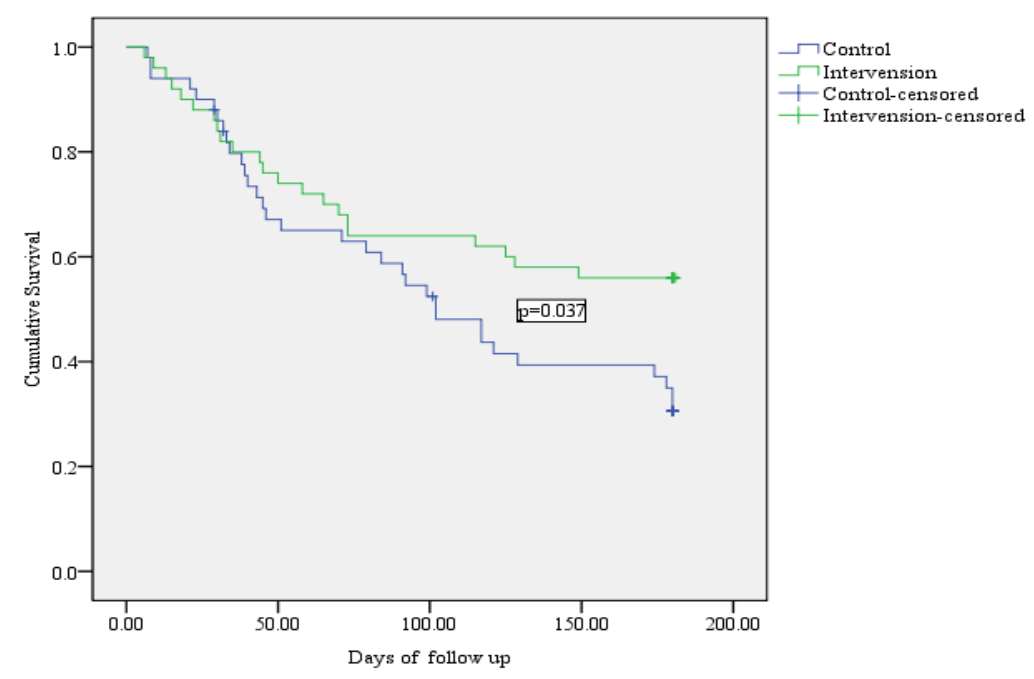

Figure 1. Cumulative survival of the patients with heart failure during study follow up 6 months

Table 2 summarizes the time of survival, and clinical outcome of re-admission and/ or mortality rates for the participants on intervention group and control group. Based on Log Rank test, after 6 months of intervention of integrated education and counseling of heart failure self-care "PrOMiSe" model, there were significantly fewer patients in the intervention group who experienced re-admission and/ or mortality (22 vs 33, $\mathrm{p}=0.037$ ). Furthermore, $56 \%$ of theparticipants in the intervention group survived duringthe studyperiodafter 6 months, with amediansurvivalof 125,420 days, much longerthan the control groupwith 107,408 days. Figure 1 shows the Kaplan-Meier curve. The survival of participants in the intervention group clearly showed that they are morelikely to be stable compared to the participants in the control group. In the control group, the survival began to decrease after \pm 70 days of intervention model but tend to be stableafter \pm 120 days. 


\section{Table3.Relative risks of clinical outcome of re-admissionand/ ormortalityrates in intervention group and control group after 6 months ofintervention of education and counseling of heart failure self-care model "PrOMiSe"}

\begin{tabular}{lcccrcc}
\multicolumn{1}{c}{ Variable } & & & & & \\
& $\mathrm{B}$ & $\mathrm{SE}$ & $\mathrm{Sig}$. & $\operatorname{Exp}(\mathrm{B})$ & $95 \% \mathrm{CI}$ \\
\hline $\begin{array}{l}\text { Intervention } \\
\text { group }\end{array}$ & -.566 & .276 & .040 & .568 & $.330-$ & .975 \\
\hline ! control as the comparison & & & & &
\end{tabular}

Table 3 describes the relative risk for clinical outcome re-admission and/ or mortality using the statistical testCoxregression. Relative risk of re-admission and/ or mortality of participants in the intervention groupranged from $0.568(95 \% \mathrm{CI}, 0.330-0.975)$, which was significant $(\mathrm{p}<0.05)$.

\section{Discussion}

The objective of this study was to determine whether patients with heart failure who receive integrated education and counseling of heart failure self-care "PrOMiSe" model led by trained cardiovascular nurses would experience fewer heart failure-related hospital re-admissionand/ ormortality and increase survival time than the patients with heart failure who receive usual care. Allpatients enrolled inthis study, either in the intervention grouporthe control group, receivedastandardheart failuretreatmentin accordancewith theconditions ofthepatientsuch as; treatment $\beta$-Blockers, ACE inhibitors, angiotensin receptor antagonist and aldosterone receptor antagonist all inhibit the steps in the renin-angiotensin-aldosterone system (RAAS).Most of the subjects in this study represented older participants, lower ejection fraction, and most of patients with heart failure due to hypertension who are vulnerable for inadequate self-care, frequent heart failure related readmission and higher mortality rates.

Statistical analysisshowed thatthe integrated education and counseling of heart failure self-care "PrOMiSe" model is effective toprolong survival and decrease re-admission and/ or mortality on after 6 months of undergoing interventionmodel. This result confirmed with study of the effect of an advanced practice nurseled telephone intervention on outcomes of patients with heart failure that found advanced practice nurse-led telephone intervention positively impacts outcomes of patient with heart failure, particularly by improving selfcare behaviors and decreasing hospital re-admission. ${ }^{9}$ Each telephone call for pre-testing and post-testing ranged from 25 to 30 minutes. The theoretical basis of Brandon study was Orem's self-care deficit theory. Through the educative/supportive system, the advanced practice nurse address those self-care deficits and empowers the patients to practice healthy self-care behaviors. The investigation was a pretest-posttest experimental design in which twenty participants were randomly assigned to either an experimental group or control group, while researcher used a three models integrated approach are Transtheoretical, Orem and Motivational Interviewing model is named "PrOmiSe" model. In addition, on intervention group received 5 education sessions and counseling duringhospitalization, 3 education and counseling sessionsand counseling in out patient clinic and two telephone calls over a three months period, and as well as intervention group provided 5 booklets (written material about heart failure self-care) and 2 monitoring books about monitoring drugs therapy, and weight and fluids monitoring. Each education and counseling was performed for 45-60 minute. Meanwhile, each telephone call for education and counseling was performed for 5-10 minutes. Control group receive 1 time education as a usualwithout written material. This interventionwas provided by the project cardiovascular nurse. The clinical experience of the project cardiovascular nurse consisted of 10 years as clinical nurse working in cardiovascular care unit. The project cardiovascular nurse received training that included a 6-hour session regarding of instruction the integrated education and counseling of heart failure self-care model "PrOMise" with the researcher, 6-hour session regarding the management of heart failure by a cardiologist; and a 12-hour session regarding the concept, theory and strategy of education and counseling by a psychologist and a nurse consultant. Although these studies have different methods, they all show result that intervention education by nurse could significantly reduce the hospital re-admission and/ or mortality rates after receiving the intervention.

The findings of this study also supported from previous a systematic review and meta-analysis of 8 randomized controlled studies comparing re-admission rates and mortality rates in patient with heart failure which the pooled analyses for re-admission demonstrated that an education intervention in patient with heart failure as part of a program resulted in statistical significant relative risk reduction in hospital re-admission using a random effects model was $0.79(95 \% \mathrm{CI}, 0.68-0.91 ; \mathrm{p}<0.01)$. In contrast, there were no apparent effect on mortality (relative risk $0.98,95 \mathrm{CI}, 0.72-1.34 ; \mathrm{p}=0.90$ ). ${ }^{12}$ The intervention which in these studies were varied such as: at least home visit within 1 to 2 weeks of discharge from hospital, the nurse telephone once per months for duration of follow up, and the intervention was conducted by mail and follow up was conducted by a telephone performed by non-medical personnel. 
Moreover, this research finding was consistent with previous finding (Blue, 2001) were heart failure related hospital re-admission significantly improved with giving education to the patients by specially trained nurses.$^{7}$ Another previous finding (Strömberg, 2002) demonstrated that there were fewer patients with events (mortality or admission) after 12 months in the intervention group compared to the control group (29 vs 40 , $\mathrm{p}=0.03$ ). It is clear that follow up after hospitalization at a nurse-led heart failure can improve survival and selfcare behavior in patients with heart failure as well as reduce hospital re-admission. ${ }^{13}$

Our study result shows that the integrated education and counseling of heart failure self-care "PrOMiSe" model significantly prolong the survival and decrease the rates clinical outcome of hospital readmission and/ or mortality in after 6 months of undergoing intervention model. It is likely to be related to the intervention model already applied on first three months. Before conducting this study, the nurses who will provide education and counseling of heart failure self-care "PrOMiSe" model received training approximately 24 hours. Patients must be assured of basic knowledge of heart failure self-management skill before they discharged from the hospital. The nurse should have the knowledge and the skill to assess self-care deficits and to develop an educational plan. Nurses who are better prepared to educate patients with heart failure may more likely to carry out this nursing function as a part their daily role. As a mentioned in research finding (Albert, 2002) that nurses may not be properly educated in heart failure self-management principles. Nurse must be provided with the right information so they can improve the quality and amount of information they offer to patients. ${ }^{15}$

Successful self-care management in heart failure often requires lifestyle changes such as weigh daily, check ankle for swelling, avoiding getting sick, eat a low salt diet, reduce fluid intake, exercising regularly and see a doctor or nurse, follow the treatment advice. Moreover, based on the concept of transtheoretical model, a framework for making behavioral changes, proposes that change requires a series of stages, in this study all participants were assessed on the stage of changes by using stage of change questionare instrument evaluation to get an initial stage of change of each participants to specify properly education needs. In line with previous study which mentioned use of the stage of change tool to asses stage of readiness to make self-care management changes. ${ }^{16}$

Before patient with heart failure can determine the appropriate self-care behavior to engage in, they must gain knowledge on elements specific to their situation. The patient with heart failure faces challenges of adapting self-care behavior to maintain health, with the additional self-care required due to heart failure. If the patient has a knowledge deficit related to heart failure self-care behavior, the action of self-care cannot take place, in turn leading to a self-care deficit. Self-care deficit may occur because of lack of heart failure symptom knowledge, poor diet selection, excess fluid intake, and as well as not follow treatment advise. Through the education/supportive system, the trained cardiovascular nurse address those self-care deficits and empower the patient to practice healthy self-care behavior. ${ }^{9}$

Optimal patient education and counseling involve more than simply providing information. Counseling emphasizes individualized delivery of important information, taking into account the factors discussed previously that interfere with successful participation in care such as language, cognitive function, mood, as well as a patient's readiness to change. Internal motivation is an important factor contributing to successful self-care, and motivational technique are extremely effective for individuals in one of the early stage of change. Motivational interviewing, a technic that emphasizes helping the patient resolve ambivalence about change, is effective even for those with difficult behaviors such as for persons with heart failure. ${ }^{17}$ Therefore, it is clear our study used Orem's theory, particularly by providing education, and as well as motivational interviewing approach to improving heart failure self-care, and decreasing clinical outcome hospital readmission and/ or mortality.

Educational and counseling intervention on intervention group conducted by trained cardiovascular nurse was a one-on-one, received four teaching sessions within five days of hospitalization. They conducted a patient assessment prior to implementing their strategy. Participants may have different learning needs influenced by factors such as time since diagnosis and previous participant education. It is widely acknowledged in education literature that effective education program are based on a comprehensive needs assessment. ${ }^{17}$ Regarding with teaching session, researcher used educational needs assessment and evaluation form, five booklets of heart failure self-care, two monitoring books about monitoring drugs therapy, and weight and fluids monitoring, a flip chart, poster, weigh scale, urinal, one bag of five grams of sodium, as well as measuring cup for drink. This study in line with previous finding. ${ }^{8,19}$ Alongwiththeprovisionofeducational,motivational counselingisalso performed on intervention group, which a lesson was given dependson thereadiness ofstageof thechanges. Thecontinuededucationand counselingaregivenduring patient visit in clinic andbytelephoneevery two weeks interval in the period three months.

Our study was supported with previous finding (Naji, 2009), which demonstrated that treatment of patient with heart failure needs long term control and the patient who can gradually improve their condition. To achieve this situation, the results of Naji study showed that applying Orem's model of self-care is very effective 
for patient with heart failure. It resulted in higher score of self-care, less referral, and. less hospitalization. ${ }^{20}$ Another supported previous finding mentioned an intervention that incorporates the core elements of motivational interviewing may be effective in improving self-care. ${ }^{21,22,23}$

\section{Conclusion}

Heart failure is characterized by high rate of hospital re-admission and/ or mortality. It is essential that effective behavior change strategies be given to patients along with provision of education and counseling. Knowing patient's readiness to change, and encouraging internal motivation is important factor contributing to successful self-care in heart failure patients. The education and counseling intervention, which integrated transtheoretical, Orem and motivational interviewing model, as specifically designed (PrOMiSe" model) led by trained cardiovascular nurse has proven effectively increase time of survival and decrease hospital re-admission and/ or mortality in heart failure patient. This "PrOMiSe" model is expected to be one of integrated education and counseling of heart failure self-care model which can be developed and replicated in other hospitals in Indonesia.

\section{Acknowledgements}

This study was supported by a research grant from the National Cardiac Center Hospital "Harapan Kita”, Jakarta, Indonesia.

\section{References}

[1] Fuster,Valentin.,Alexander R.Wayne.,O’Rourke RobertA.,et al.Hurst's The Heart. Tenth Edition. USA: McGraw-Hill, 2001.

[2] Kannel WB, Ho K, Thom T. Changing epidemiological features of cardiac failure. Br Heart J, 72, 1994, S3-S9.

[3] Hunt Sharon Ann., Abraham William T., Chin Marshall H., et al. ACC/AHA 2005 Guideline Update for Diagnosis and Management of Chronic Heart Failure in Adult. Downloaded from Circulation American HeartAssociation Journal.org by on August 19, 2008.

[4] Artinian, Nancy.T., Magnan Morris., Christian Willecia., et al. What Do Patients Know About Their Heart Failure?.Applied Nursing Research, Vol. 15, No 4 (November), 2002, 200-208.

[5] Data Devisi Rekam Medik tahun 2008-2009 tentang kejadian Gagal Jantung yang dirawat di Rumah Sakit Jantung dan PembuluhDarah Harapan Kita.

[6] De Geest Sabina. Another Perspective in Understanding Adherence. Qualitative Research in Unraveling The Behavioural Dimention of Heart Failure Management. Journal of Cardiopulmonar Rehabilitation, 25, 2005, 164-165.

[7] Blue Lynda., Lang Elanor., McMurray John JV., et al. Randomised Controlled Trial of Specialist Nurse Intervention in Heart Failure, BMJ, Vol. 323, 2001.

[8] Boyde, Mary., Turner Catherine., GradDipEd., et al. Educational Interventions for Patients With Heart Failure; A Systematic Review of Randamized Controlled Trials. Journal of Cardiovascular Nursing,Vol. 26, No. 4, 2011, pp E27-e35.

[9] Brandon Amy F., Schuessler Jenny B., Ellison Kathy Jo., et al. The effect of an advanced practise nurse led telephone intervention on outcomes of patients with heart failure. Applied Nursing Research. 22, 2009.

[10] Caldwell Mary A., Peter Kathryn J., Dracup Kathleen. A Simplified Education Program Improves Knowledge, Self-Care Behavior, And Diseases Severity in Heart Failure Patients in Rural Settings. American Heart Journal, November, 2005.

[11] Grange, J. The Role of Nurses in The Management of Heart Failure. Heart,91(Suppl II), 2005, :ii39-ii42. doi:10.1136/hrt.062117.

[12] Gwadry Sridhar., Flintoft Virginia., Guyatt Gordon H. A systematic review and Meta-analysis of Studies Comparing Readmission Rates and Mortality Rates in Patients With Heart Failure. Arch Intern Med, 164, 2004, 2315-2320.

[13] Stormberg A., Martensson J., Fridlund., et.al. Nurse-led heart failure clinics improve survival and self care behaviour in patients with heart failure. European Heart Journal.24, 2003, 1014-1023.

[14] GrancelliH., Varini S., Ferrante D., et al. Randomized Trial of Telephone Intervention in Chronic Heart failure (DIAL): Study Design And Preleminary Observation. J Card Fail,9 (31), 2003, 172-179.

[15] Albert Nancy M., Collier Susan., Sumodi Veronica., et al. Nurses' Knowledge of Heart Failure Education Principles, Heart \&Lung, 2003, March/April.

[16] Paul Sara., Sneed Nancee V.Strategies for Behavior Change in Patients with Heart Failure, American Journal of Critical Care, $13,2004,305-313$.

[17] Moser Debra K., Riegel Barbara.Heart Failure ManagementA Companion to Baraunwald's Heart Diseases; DiseaseManagement in Heart Failure Canada: Saunder Elsevier.Inc, 2011.

[18] Lorig K. Patient Education A Practical Approach. Thousand Oaks, CA: Sage Publications, 2001

[19] Caldwell Mary A., Peter Kathryn J., Dracup Kathleen. A Simplified Education Program Improves Knowledge, Self-Care Behavior, And Diseases Severity in Heart Failure Patients in Rural Settings. American Heart Journal, November, 2005.

[20] Naji Homayun., Nasrabadi Alireza Nikhbakht., Shaban Marzieh., et al. The Effect of Using Orem's Model of Self Care on Recover of Patients with Heart Failure. IJNMR, 14(4), 2009, 174-179.

[21] Moser Debra K., Watkins John F. Conceptualizing Self Care in Heart Failure. Journal of Cardiovascular Nursing, Vol 23, N0 3, 2008, 205-218.

[22] Paradis Veronique., Cossette Sylvie., Smith Nancy Frasure., et al. The Efficacy of a Motivational Nursing Intervention Based on The Stages of Change on Self-care in Heart Failure Patients. Journal of Cardiovascular Nursing, Vol. 25, No.2, 2010, 30-141.

[23] Riegel Barbara., Dickson Victoria Vaughan., Hoke Linda., et al. A Motivational Counseling Approach to Improving Heart Failure Self Care. Journal of Cardiovascular Nursing,Vol. 21, No. 3,2006, 232-241. 